\title{
Histological changes of CA and DG regions of hippocampus of rats' brain after exposure to Acetaminophen in postnatal period
}

\author{
S.M. Albo Hussin ${ }^{\circ}$ and L.I. Al-Allaf $\mathbb{C}^{\circ}$ \\ Department of Anatomy, College of Medicine, University of Mosul, Mosul, Iraq
}

\begin{tabular}{l} 
Article information \\
\hline Article history: \\
Received February 20, 2021 \\
Accepted May 26, 2021 \\
Available online November 22, 2021 \\
\hline Keywords: \\
Acetaminophen \\
Rat \\
Brain \\
Histology \\
\\
\hline Correspondence: \\
L.I. Al-Allaf \\
lumaallaf1971@yahoo.com
\end{tabular}

\begin{abstract}
Authors reported that exposure to acetaminophen postnatally may be linked to increasing the risk of ASD. However, the reports on its effects on the brain are scanty, and the knowledge concerning their safety is little as there is a traditional left out of the clinical trials by users. The present work tried to elucidate the histological effects of acetaminophen on the hippocampus of neonate male rats after early postnatal exposure. The pups were categorized into 2 groups, the control group, and the acetaminophen treated group. The acetaminophen treated animals were injected subcutaneously with acetaminophen of $60 \mathrm{mg} / \mathrm{Kg} /$ day from postnatal day (PND) 7 to PND 14, while the control group treated with normal saline with a similar approach. The histopathologic assessment revealed a diminishing in the pyramidal cells layer thickness of Cornue Ammonis. Some areas are devoid of cells with the appearance of Ghost like cells indicating features of neural cell death, degenerated neurons in the pyramidal layer are noticed. Features of nuclear clumping of pyramidal cell layer were shown. Moreover, several changes including vacuolations in the granular layer of DG with disorganization in DG. Neuronal processes presented with clumping. Apoptosis in the granular cells layer and hilus of a section of DG with the appearance of many astrocytes and microglial cells. Exposures to clinically relevant doses of acetaminophen in the postnatal period were shown to affect the histology of rat hippocampal regions, and a balanced risk assessment based on the best professional judgment must be prioritized.
\end{abstract}

DOI: 10.33899/ijvs.2021.129569.1664, (A)Authors, 2022, College of Veterinary Medicine, University of Mosul.

This is an open access article under the CC BY 4.0 license (http://creativecommons.org/licenses/by/4.0/).

\section{Introduction}

The exposure to analgesia during pregnancy, at neonatal period, and childhood is frequent. However, the knowledge concerning their safety is little as there is a traditional left out of the clinical trials by users (1). Recently, antenatal administration of paracetamol (Acetaminophen, N-Acetylp-Aminophenol) has been associated by attention deficit hyperactivity disorder (ADHD) or spectrum of autism disorders (ASD), language delay, and lower IQ (2). Moreover, authors reported that exposure to acetaminophen postnatally may be linked to increasing risk ASD (3). The process of actions of acetaminophen is not clear yet, beside the fact that acetaminophen (paracetamol) is the $1^{\text {st }}$ drug to treat pain and fever throughout gestation and childhood, in addition to the increasing reports of the developmental effects, all these factors are urging for researches for its effects on neurodevelopment (1). Acetaminophen is one of the most over the counter analgesic and antipyretic agent (4). The misuses of it lead to hepatic or renal damage (5). Throughout the development of the brain, there is development of layer of cells to form a complicated system of billions of specified cells under time control which is the most vulnerable period to toxic substances. However, the brain is well protected physically but there is chemical that may pass through the blood- brain - barrier and induce several adverse effects either involuntary or deliberately (1). Most of the studies have been focused on the antenatal 
exposure and neglect the vital period of fast brain developmental period that happens postnatally in experimental animals and in perinatal period in human as the rodents are considered as an attracting model for human (1). The critical period in human happens in the last trimester of gestation to the second year of life which represented postnatal period in rodents from birth to day 30 with the peak at day $10(1,6)$. Acetaminophen metabolism is by hepatic cells by conjugation with sulphate and glucuronic acid, while its excretion is by kidneys. When there is an excessive amount of metabolite (NAPQI), there is a liver damage due to oxidative stress (7). Interestingly, the isoform of Cytochrome P450 (CYP2E1) will be expressed within the brain cells supporting the concept that acetaminophen (as it passed through the Blood Brain Barrier -BBB) may be metabolized by brain and producing the harmful NAPQI (8). Limbic system has a neural portion of the brain -Hippocampus -that is concerned with memory and learning in both human and animals (9), and it lies in temporal lobe (medially) with a specialized curve of $S$ shape. In general, the gateway to memory- Hippocampal formation has complicated 6 parts: The dentate Gyrus (DG), Hippocampus Proprius, Subiculum Proprium, Presubiculum, Parasubiculum, and entorhinal area (10). Cornu Ammonis was found in the hippocampus proper as CA1 and CA 2 constituted of area of small Pyramidal cells, while large Pyramidal cells was found in CA3 and CA4 regions. CA4 directed into concaveness of DG and constituted of small granule cells. The continuation of CA1 zone-Subiculum and is directed outward. Hippocampus has generally the three zones; polymorphic, pyramidal, and molecular (11). On the other hand, the DG formed of 3 zones: Molecular, Granular and the Hilus which is represented the Polymorphic layer. Granule cells -Chief neurons - in the DG are having typically the characteristic features of small neurons. They are arranged succinctly to make the inferior blade beside the superior one in DG of the rat. Subgranular zone (SGZ) was located in Granule cell layer and directed to the Hilus. The cells in Hilus are resembling the spiny pyramidal neurons in their morphology $(12,13)$. Hippocampus is a brain region that has been implicated in many functions such as mediating negative feedback of the hypothalamus pituitary axis (HPA), regulating behavioral measures of anxiety and spatial navigation learning. Due to all of these functions, abnormal hippocampal development may stand behind several abnormalities in the cognitive performance later in life (10). It was documented that hippocampus, including DG, exhibits well morphological plasticity in adulthood. Few brain regions that continue their capability to form new neurons during adult life in some mammalian species (including humans) and hippocampus is one of them (11). Treatment with many agents including drugs may have associated with impairments in cognition and psychologyparticularly -the memory task -that depends on hippocampus because the adverse effect of them on Hippocampal neurogenesis $(11,14)$. The hippocampal formation has an integral zone - dentate gyrus (DG) -which is simple cortical part which has the ability to retain neurogenesis throughout adulthood (13). It is thought that the neurogenesis in the DG has a crucial role in hippocampus-dependent learning and memory (12,13). So, DG contributes to new memories beside other functions (15).

In fact, there are extensive studies on the adverse effects of Acetaminophen on the hepatic and renal cells, however, the reports on its effects on the brain are scanty. The present work tried to elucidate the histological effects of acetaminophen on the rat's hippocampus after early postnatal exposure.

\section{Materials and methods}

\section{Animals}

This is an experimental case-control study which was performed in a period from $1^{\text {st }}$ December, 2020 to $1^{\text {st }}$ March, 2021 in order to investigate the histologic effects of neonatal exposure to acetaminophen on male rats' brains rats and it is enrolled Albino pregnant rats which were obtained from the animal house of College of Veterinary Medicine/University of Mosul/ Mosul/Iraq. They were maintained in plastic lab cages and observed daily for birth, then beyond their births, the pups (males and females) were categorized into litters as ten pups in each. Generally random male $\operatorname{pups}(\mathrm{n}=10)$ were injected subcutaneously by acetaminophen of $60 \mathrm{mg}$ per $\mathrm{Kg}$ per day from postnatal day 7 to postnatal day 14 in their loose skin over the neck (1), while another group of ten pups were injected by normal saline with similar approach and were considered as controls. The present work enrolled data of only male albino rats and not the females in order to be away from the hormonal effects in females. The sample size was estimated according to that of the following formula of Bano et al (16): $n 1=\left(\left(Z_{1-\beta}+Z_{1-\alpha / 2}\right)^{2}\left(\sigma_{1} 2+\sigma_{2} 2\right)\right) /(\mu 1-\mu 2)^{2}$

\section{The dose of Acetaminophen}

Acetaminophen (600 mg per ml per ampoule- QIAGEN -Germany) was bought from private pharmacies and was roughly the dose of it compatible with a human equivalent dose (HED) of $4.9 \mathrm{mg} / \mathrm{kg}$ by the use of the body surface area (BSA) adjustment method $(1,17)$. In brief, the calculation is based on each species having a different converting factor $(\mathrm{Km})$, expressed as body weight $(\mathrm{kg})$ divided by BSA $\left(\mathrm{m}^{2}\right)$, which is used to convert the dose $(\mathrm{mg} / \mathrm{kg})$ in one species to dose $(\mathrm{mg} / \mathrm{kg})$ in another species. To obtain a HED, the following equation can be used; $f \times$ $\mathrm{mg} / \mathrm{kg}=\mathrm{mg} / \mathrm{m} 2$, where $\mathrm{f}$ is $=6.0$ in rats $(1,17)$. These dose comparisons were made using the guidelines of the United states department of health and human services, food and drug administration [available here]. Recommended doses 
of acetaminophen in neonates and toddlers (and even preterm neonates) are up to four times of $7.5-15 \mathrm{mg} / \mathrm{kg}$ per day (18).

\section{Study ending and histopathological assessment}

After the termination of experimental period (PND 30) and for histopathological evaluation- brains were dissected out and fixed in $10 \%$ buffered formalin for 2 weeks from control and acetaminophen-treated animals. Specimens were washed and rinsed tap water. Separation of the hemispheres of cerebrum (right and left). Then, the hippocampus was harvested from the posterior part of the brain. Ten percent of formalin was used to fix the right hippocampus for 10 days. Dehydration (by serial dilution of ethyl alcohol), clearing (by xylol), and paraffin embedding of specimens were performed. Parasagittal sections of five microns $(\mu \mathrm{m})$ were taken for all blocks to be ready for $\mathrm{H} \& \mathrm{E}$ staining (19-21) to be ready for blinded examination under Bright field Olympus light microscope(Japan)light microscope. The photomicrographs of structural changes were obtained by digital camera attached via plan apochromatic objectives.

\section{Results}

This study included histological examination of sections which were obtained from the hippocampus of 20 rats which were categorized into two groups: control group and acetaminophen group. The histopathologic assessment of sections of rats that were belonged to control group via hematoxylin and eosin stains revealed characteristically the zones of hippocampal formation including: Hippocampus proper, DG, and subiculum (Figure 1). Sections of Hippocampus proper showed an area of small sized pyramidal cells in Cornu Ammonis CA1 and CA2 regions, while an area of large sized pyramidal cells is seen in CA3 and CA4 regions and is directed toward the concave part of DG (Figure 2). Subiculum is outward continuation of CA1 region. Cornu Ammonis in sections of rat in control group showed the presence of three diverse layers: polymorphic, pyramidal, and molecular. The pyramidal cells appear with large vesicular nuclei (Figures 3 and 4). Light microscope examination of hippocampal sections of control rats revealed that DG is formed from Molecular layer, Granule cell layer and the Hilus which formed both blades (upper and lower) (Figure 5). The granule cell layers constituted from closely packed organized granule cells beside an immature neuron that have oval dense nuclei and located in SGZ (Figure 6). On the other hand, hilar cells were seen in the Hlius as large sized cells and possess elongated processes, Glial astrocytic cells, and microglial cells (Figure 7). On the other hand, L/M examination of the hippocampal sections of rats that were received $60 \mathrm{mg} / \mathrm{kg}$ of acetaminophen subcutaneously for 7 days showed a reduction in the pyramidal layer thickness of Cornue
Ammonis (Figure 8). There are areas that are devoid of cells with appearance of Ghost like cells indicating features of neural cell death of hippocampal pyramidal (Figure 9), while degenerated neurocytes in pyramidal layer are noticed among very few healthy cells (Figure 10). Presence of large neurons (Figure 11), and astrocyte was seen in in the molecular layer of these sections (Figure 11). Feature of nuclear clumping of pyramidal cell layer (Figure 12) was shown also in the hippocampal sections of rats that were received $60 \mathrm{mg} / \mathrm{kg}$ of acetaminophen subcutaneously for 7 days.

Moreover, L/M examination of sections from Dentate gyrus (DG) of rats which were injected with acetaminophen indicated that these section exhibited several changes including vacuolations in the granular layer of DG (Figure 13) with disorganization in DG (there is cells with pale stained nuclei and other with dark) (Figure 14). Neuronal processes presented with clumping (Figure 14). Features of apoptosis were noticed in the granular layer and hilaus of section of DG of rats in acetaminophen group (Figure 15) with appearance of many astrocytes and microglial cells (Figure 16).

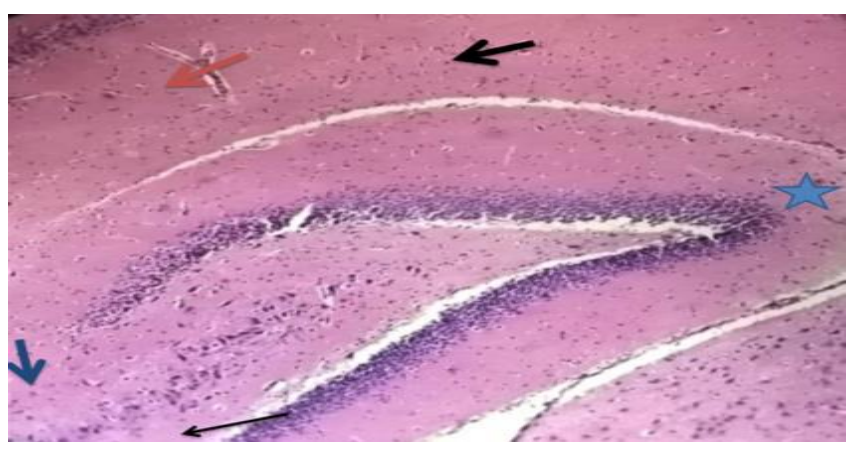

Figure 1: A photomicrograph of a hippocampal section of control group shows $\mathrm{C}$-shaped hippocampus consists of the Cornu Ammonis (CA) in the form of CA1(Thick black arrow), CA2(red arrow), CA3(blue arrow), CA4(thin black arrow) and DG(star) (H and E X 250).

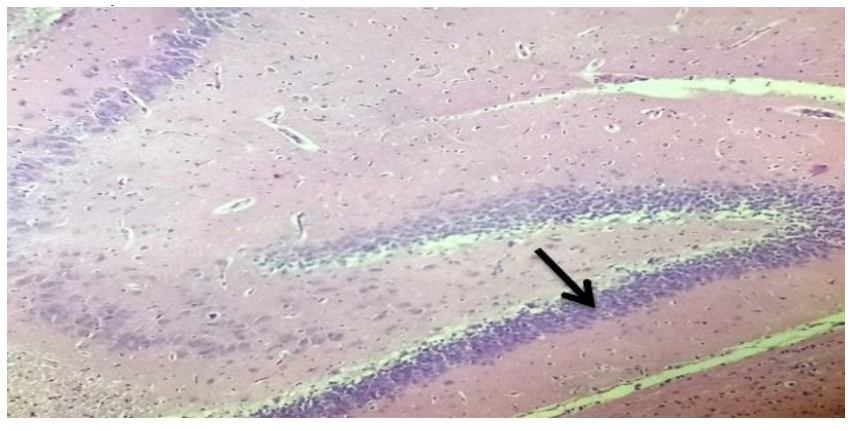

Figure 2: The pyramidal cell layer is replaced by granule cell layer (arrow) in DG in a photomicrograph of a hippocampal section of control rat (H\&E X250). 


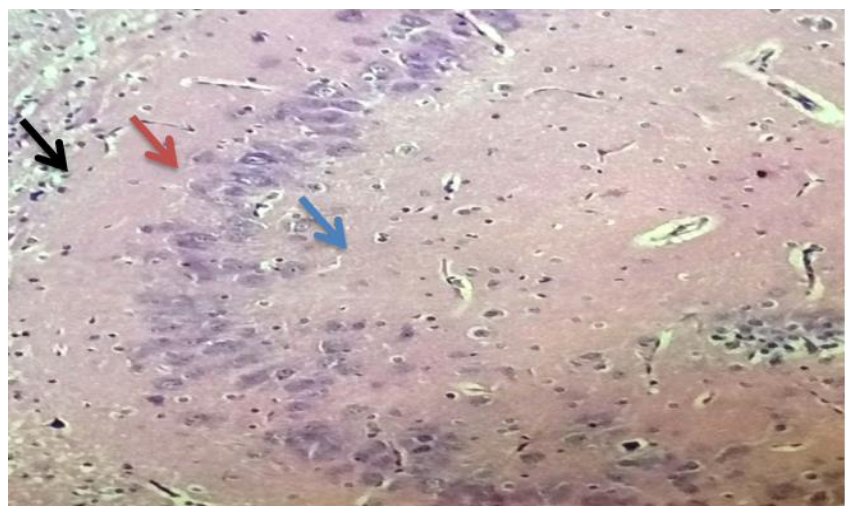

Figure 3: A photomicrograph of a hippocampal section of control rat. Three layers polymorphic (black arrow), pyramidal (red arrow), and molecular (blue arrow). The pyramidal cells appear with large vesicular nuclei $(\mathrm{H}$ and $\mathrm{E}$ $\mathrm{X} 400)$.

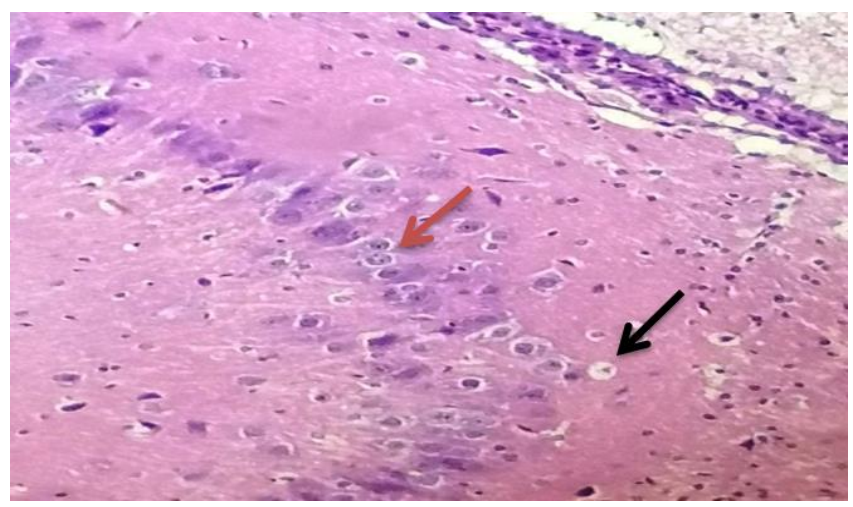

Figure 4: A photomicrograph of a hippocampal section of control rat in CA1 region with pyramidal (red arrow), and interneuron cells (black arrow) (H and E X 400).

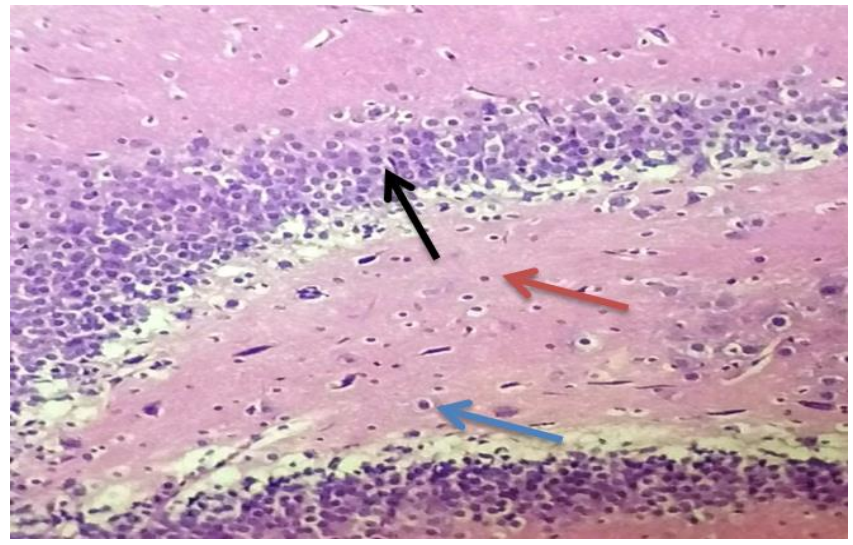

Figure 5: A photomicrograph of a hippocampal section of control rat with compact layers of granular cells (black arrow) with dark nuclei in DG. Glial cells astrocyte (blue arrow) with microglia cell (red arrow) (H \& E x400).

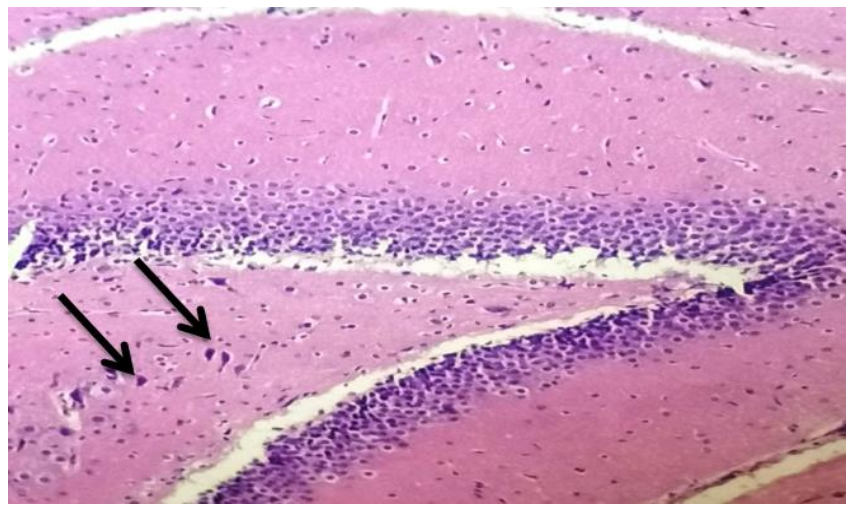

Figure 6: A photomicrograph of a hippocampal section of control rat. Note the hilar cells in DG (black arrow) (H \& E $\mathrm{x} 400)$.

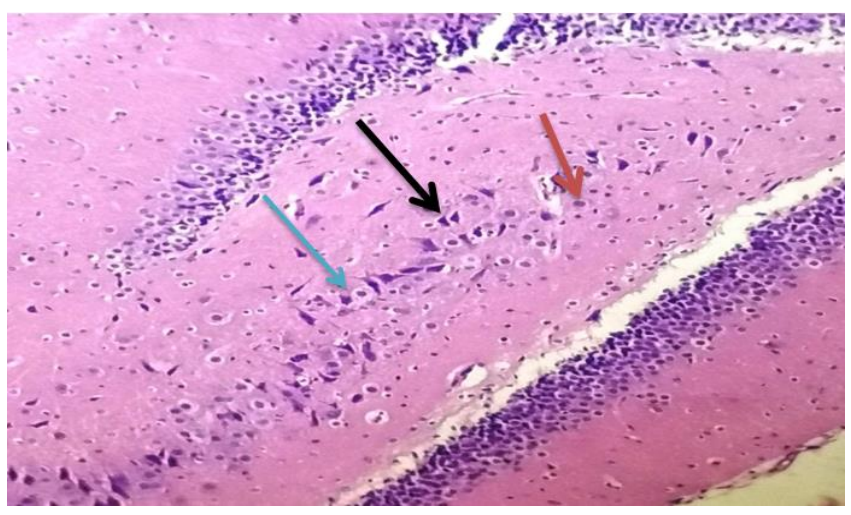

Figure 7: A photomicrograph of a section in DG of control group showing the Hilus containing good arrangement of hilar cells with elongated processes (black arrow). Note the astrocytes (blue arrow) and microglial cells (red arrow) (H\&E X400).

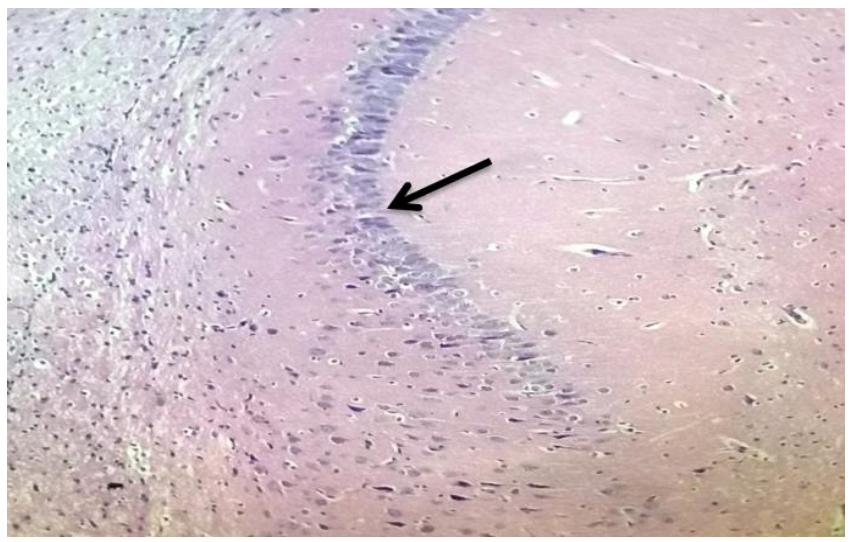

Figure 8: A photomicrograph of a hippocampal section of rat from the acetaminophen group with the reduction in the thickness of the pyramidal layer of Cornue Ammonis (CA3, $\mathrm{CA} 4)$ (arrow) (H and $\mathrm{E} \times 250)$. 


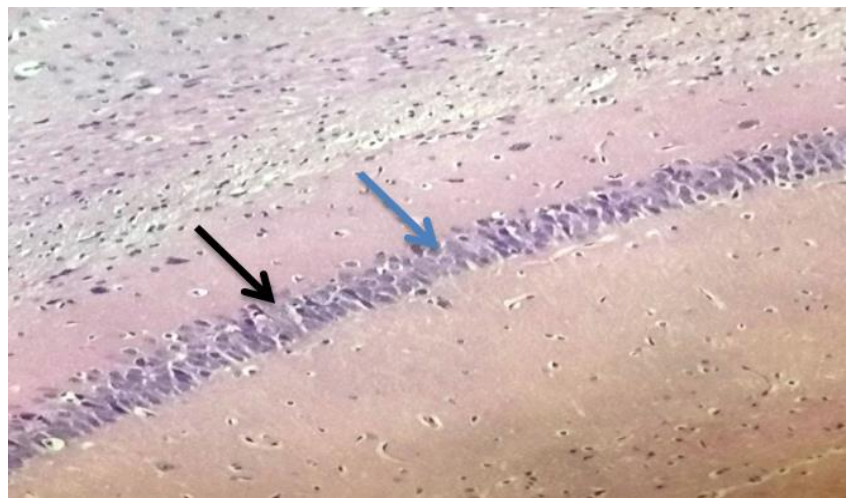

Figure 9: The effects of Acetaminophen in a section from Cornu Ammonis of rat revealing areas devoid of cells (arrow) with Ghost like cells (blue arrow) indicating features of neural cell death of hippocampal pyramidal via hematoxylin-eosin staining at 400x magnification.

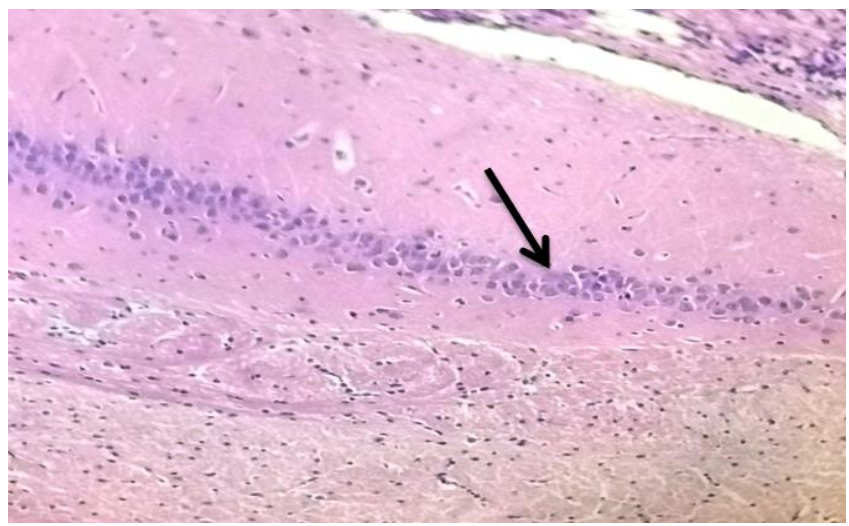

Figure 10: A photograph of a hippocampal section from rat of acetaminophen group degenerated neurocytes in pyramidal layer (arrow) among very few healthy cells (H and $\mathrm{E} x$ 400).

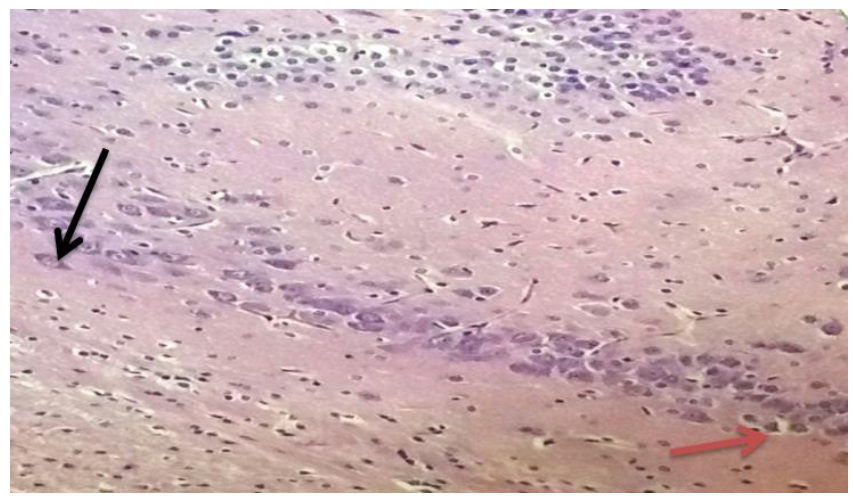

Figure 11: A photograph of a section of hippocampus from rat that was received acetaminophen. Note the presence of large neurons (black arrow), and astrocyte (red arrow) in the molecular layer ( $\mathrm{H}$ and $\mathrm{E} \times 400)$.

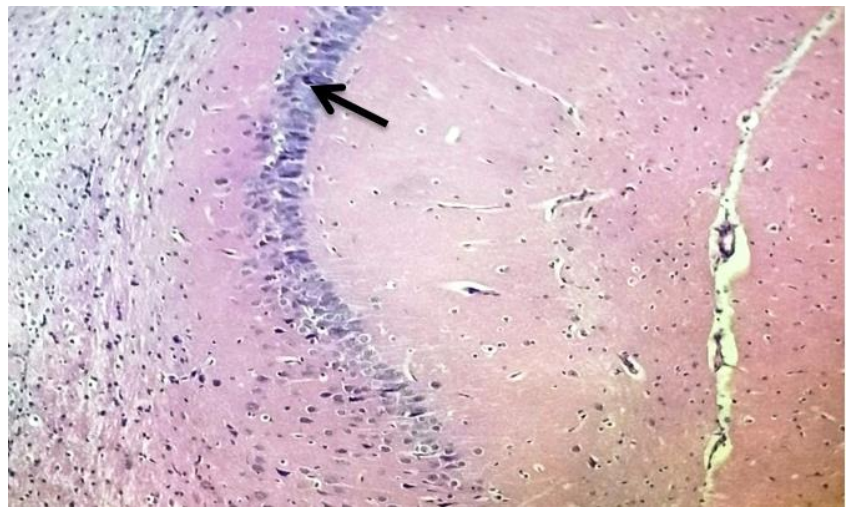

Figure 12: A photograph of a hippocampal section from rat belonged to acetaminophen group with nuclear clumping of pyramidal cell layer (arrow). Note the decreased thickness of this layer ( $\mathrm{H}$ and $\mathrm{E} \times 250)$.

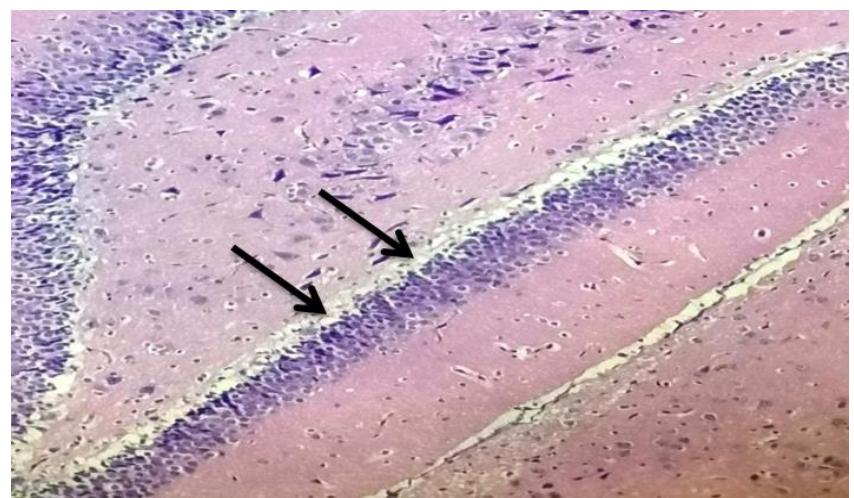

Figure 13: A photomicrograph of a hippocampal section of rat from the acetaminophen group with vacuolations (arrow) in the granular layer of Dentate gyrus (DG) (H and Ex 400).

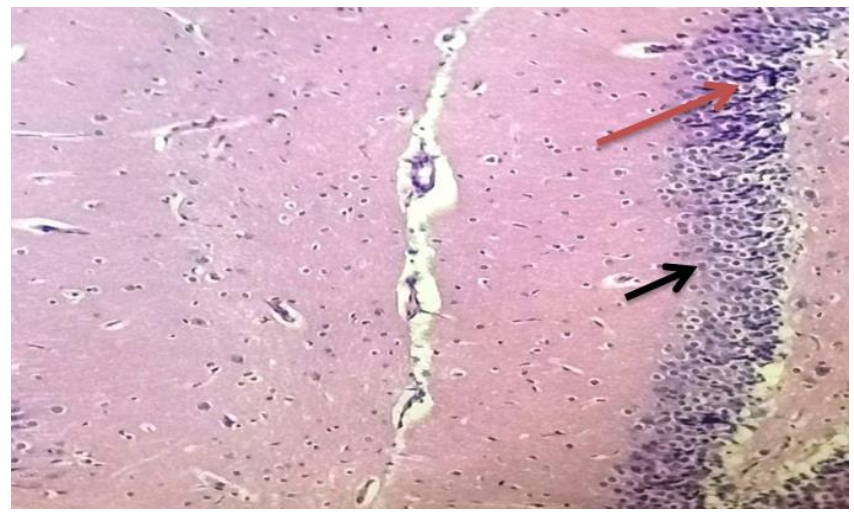

Figure 14: A photograph of a section from rat that was administered with acetaminophen with disorganization in DG. There is cells with pale stained nuclei (black arrow) and other with dark (red arrow). Neuronal processes presented with clumping (red arrow) (H and E x400). 


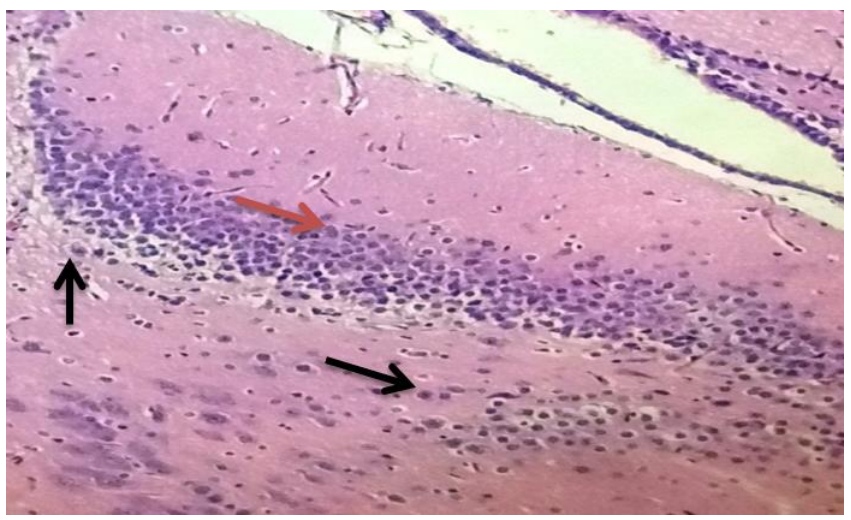

Figure 15: A photograph of a section of DG from rat that was received acetaminophen Degenerated neurocytes (granular cell layer-red arrow) separated by few healthy cells. Features of apoptosis is seen (black arrows) (H and E $\mathrm{x} 400)$.

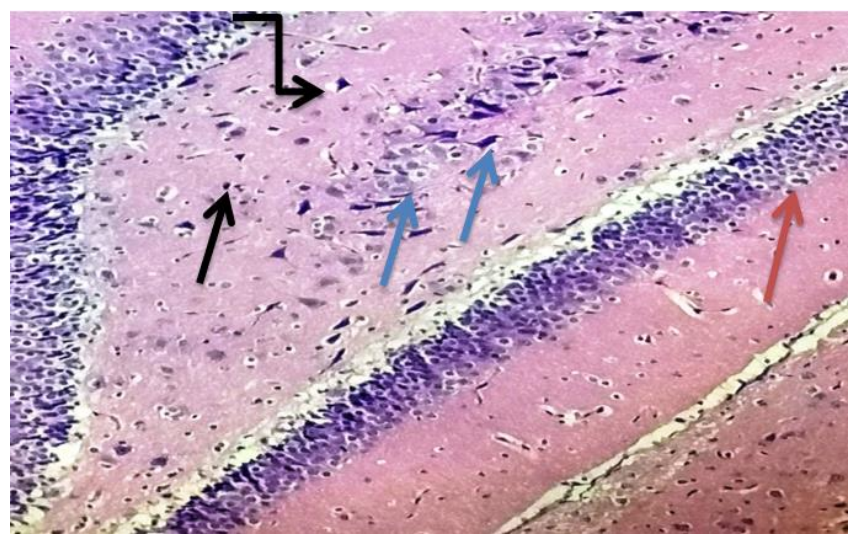

Figure 16: A photograph of a section of DG from rat of acetaminophen group. Note numerous apoptotic cells (red arrow) in granular layer and hilaus (blue arrow) with some microglial cells (black arrow) and astrocytes (curved arrow) (H and $\mathrm{E} \times 400)$.

\section{Discussion}

Long time ago, Hippocampal formation has been considered as the part of the brain that to be accountable for memory and learning and includes precise, and interconnected, categories of efferent systems for memories of episodes of our life, social and affective learning, and sensory dealing beside its integral functions. All these functions can be influenced by many agents including drugs (22). Hippocampal Cornu Ammonis 1 (CA1) is represented the most sensitized zone which is susceptible to different stimuli and among three brain zones that are commonly be vulnerable to oxidative stress and the firstly suffer from functional declining (11). On the other hand, Licht et al reported that DG, is second susceptible brain tissue that have neuronal stem cells (adult) which are accountable for neurogenesis in hippocampus for adult $(11,23)$.

The current study tried to elucidate the histologic changes of rat's hippocampus after postnatal exposure to acetaminophen via light microscope and it showed that hippocampal sections of rats which received $60 \mathrm{mg} / \mathrm{kg} / \mathrm{day}$ of acetaminophen from PND 7 to PND 14 exhibited several changes in different parts of hippocampus using $\mathrm{H}$ and $\mathrm{E}$ stains including a reduction in the thickness of the pyramidal layer of Cornue Ammonis, presence of areas that are lacking of cells, presence of Ghost like cells as an indicative features of neural cell death of pyramidal cells in hippocampus, degenerated neurocytes in pyramidal layer among very few healthy cells beside clumping pyramidal cell nuclei. These findings are consistently shown in another work which suggested that these lesions were result from damage to neurons and lead to obvious reduction in the thickness of neurocytic layer $(11,21,22)$. On the other hand, light microscopic evaluation of sections from DG region that are belonged to the rats which received 60 $\mathrm{mg} / \mathrm{kg} /$ day of acetaminophen from PND 7 to PND 14 subcutaneously revealed different changes including presence of large neurons in the molecular layer, vacuolations in the granular layer of DG with features of disorganization in DG. These observations are in accordance with those of several studies $(11,22)$.

It is well known that acetaminophen interacted with both the cyclooxygenase (COX) system, and cannabinoid receptor type 1 (CB1R) which were potentially inducing developmental neurotoxicity (DNT). An interesting study of Philippot et al. concluded that early exposure to acetaminophen resulting a decreased transcription levels of genes that encode a receptor incorporated in neurogenesis and elevated level of oxidative stress markers $(1,24)$. This may have recommended and clarified respectively mechanisms of developmental neurotoxicity and giving a novel confirmation from a rodent model that is relevant for human concluding that that exposure to this agent for single-day throughout the peak of the Brain growth spurt is sufficiently affecting learning, memory cognitive and spontaneous behavior at adulthood in rodents $(1,25)$. This study showed presence of cells with pale staining nuclei, while others have dark with appearance of neuronal processes that were characterized with clumping. Moreover, features of apoptosis (numerous apoptotic cells) in granular layer and hilaus with many microglial cells and astrocytes. These findings are similar to those of Kamar (11), who suggested that these lesions due to neurodegeneration with astrocytosis (as a reaction) in CA1 and DG regions of hippocampus of male albino rats (11).

A study of Amin reported that the presence of excess eosinophilia due to neuronal processes' clumping as indication of neurons' damage (22). In fact, the neuronal death is representing the clue in most of the neurodegenerating disorders, beside apoptosis and necrosis which 
were the core of both acute and chronic degenerative processes (22). The present work enrolled data of only male albino rats and not the females in order to be away from the hormonal effects in females as estrogen strengthened cellular proliferation throughout cycle and leads to increased immature neurons in the hippocampus because there is a possible action of the new cells on hippocampal function (13). An overdose administration with acetaminophen results a marked elevation in the level of malondialdehyde (MDA) which is related with a significant reduction in total status of antioxidant capacity in the brains of male albino rats (26) furthermore, the elevation in the levels of MDA in the brain after administration with acetaminophen at high doses relates with an increased rate of a marker of oxidative damage which is lipid peroxidation (4). On the other hand, elevation in activity of acetyl choline esterase (AChE) may be result from the damage in neuronal membrane from lipid peroxidation (27).

Interestingly, authors reported a marked effect of the chronic treatment with acetaminophen on the amino acids levels in various zones of the rat brain (4). They suggested that the abnormal alterations in different amino acids concentrations may be a result of a spectrum of actions of this agent in the CNS from the pharmacological aspect. Also, the neuronal damage and the decreased level of neurotransmitter may be a result from acetaminophen induced oxidative stress. Besides that, a study revealed that acetaminophen administration caused a marked increase in dichlorofluorescein oxidation levels, and those of of thiobarbituric acid reactive substances (TBARS) in the homogenates of brain (4). On the other hand, swollen mitochondria and reactive oxygen species formation (ROS) may increase beyond administration with acetaminophen. There is an observed acetaminophen -related declining in levels of serotonin and dopamine which leads critically to adverse side in the behavior and emotion taking in consideration their crucial function as neurotransmitters (4).

Our histological observation showed various degenerative alterations in different zones of rat hippocampus after acetaminophen treatment. These results coincided with an in vivo observations of Essawy et al who showed a harmful effect of this drug on the neurons of cerebral cortex in rats, in addition, this agent induces changes that indicate neuronal damage in granular cells of cerebral cortex (4). Acetaminophen is capable to activate the neuronal CYP2E1 thus producing toxic substances during metabolism as NAPQI (that decrease the level of glutathione and causing neurotoxicity and oxidative stress) (1), besides that, acetaminophen with overdose decreased the levels of anti-oxidants like glutathione, ascorbic acid with a relation to a significant reduction in the activity of superoxide dismutase (SOD). The important over creation of reactive oxygen species (ROS) in brain and the imbalance between oxidative stress and antioxidants are related with pathologic alterations neurodegenerative disorders $(4,28-30)$.

\section{Conclusion}

Exposures to clinical relevant doses of acetaminophen at early stages of life (from PND7-PND14) were shown histological changes of rat hippocampal regions (CA and DG). In spite of the common use acetaminophen throughout the pregnancy and early life is depended upon its advantages in comparison with the other analgesics, there is a demand for a balanced risk assessment basing on the best professional judgment that should be taken as a priority.

\section{Acknowledgments}

Deep thanks to the members of staff of Animal House in Veterinary College of Medicine, University of Mosul, Mosul, Iraq.

\section{Conflict of interests}

Both authors are declaring that there are no conflicts of interest.

\section{References}

1. Philippot G, Gordh T, Fredriksson A, Viberg H. Adult neurobehavioral alterations in male and female mice following developmental exposure to paracetamol (acetaminophen): characterization of a critical period. J Appl Toxicol. 2017;37(10):1174-1181. DOI: $10.1002 /$ jat.3473

2. Bornehag CG, Reichenberg A, Hallerback MU, Wikstrom S, Koch HM, Jonsson BA, Swan SH. Prenatal exposure to acetaminophen and children's language development at 30 months. Eur Psychiatry. 2018;51:98-103. DOI: 10.1016/j.eurpsy.2017.10.007

3. Bittker SS, Bell KR. Postnatal acetaminophen and potential risk of autism spectrum disorder among males. Behav Sci. 2020;10(1):1-14. DOI: $10.3390 / \mathrm{bs} 10010026$

4. Essawy A, Alkhuriji AF, Soffar AA. Paracetamol overdose induces physiological and pathological aberrations in rat brain. J Appl Pharm Sci. 2017;7(9):185-190. DOI: 10.7324/JAPS.2017.70925

5. Toklu HZ, Şehirli AÖ, Velioğlu-Öğünç A, Çetinel Ş, Şener G. Acetaminophen-induced toxicity is prevented by $\beta$-d-glucan treatment in mice. Eur J Pharmacol. 2006;543(1-3):133-140. DOI: 10.1016/j.ejphar.2006.05.033

6. Semple BD, Blomgren K, Gimlin K, Ferriero DM, Noble-Haeusslein LJ. Brain development in rodents and humans: Identifying benchmarks of maturation and vulnerability to injury across species. Prog Neurobiol. 2013;107:1-16. DOI: 10.1016/j.urobio.2013.04.001

7. Masoud M, Kotb A, Abd El-Raouf O, Fikry E. The neuroprotective effects of natural antioxidant against brain injury induced by paracetamol in a rat model of protein malnutrition. Egypt Pharm J. 2020;19(1):55-61. DOI: 10.4103/epj.epj_54_19

8. Joshi M, Tyndale RF. Induction and recovery time course of rat brain CYP2e1 after nicotine treatment. Drug Metab Dispos. 2006;34(4):647-652. DOI: $10.1124 / \mathrm{dmd} .105 .008029$

9. Anarkooli IJ, Ganji HB, Pourheidar M. The protective effects of insulin and natural honey against hippocampal cell death in streptozotocin-induced diabetic rats. J Diabetes Res. 2014;2014:1-8. DOI: $\underline{10.1155 / 2014 / 491571}$ 
10. Mohamed DA, Ahmed SM. Donepezil improves histological and biochemical changes in the hippocampus of adult hypothyroid male rats. Egypt J Histol. 2018;41(4):445-458. DOI: 10.21608/ejh.2018.3807.100

11. Kamar SA, Abdel Malak HW, Saad SA. Effect of caffeinated energy drinks on the structure of hippocampal cornu ammonis 1 and dentate gyrus of adult male albino rats. Anat Cell Biol. 2020;53(3):330-341. DOI: $10.5115 / \mathrm{acb} .20 .136$

12. Li B, Yamamori H, Tatebayashi Y, Shafit-Zagardo B, Tanimukai H, Chen S, Iqbal K, Grundke-Iqbal I. Failure of neuronal maturation in Alzheimer disease dentate gyrus. J Neuropathol Exp Neurol. 2008;67(1):78-84. DOI: 10.1097/nen.0b013e318160c5db

13. El-Safti F-NA, El-Kholoy W, El-Mehi A, Selima R. A comparative study on the effect of aging on the hippocampal CA1 area of male albino rat. Menoufia Med J. 2017;30(4):1079-1084. DOI: 10.4103/1110-2098.229200

14. Samuels BA, Hen R. Neurogenesis and affective disorders. Eur $\mathbf{J}$ Neurosci. 2011;33(6):1152-1159. DOI: 10.1111/j.-9568.2011.07614.X

15. Kitamura Y, Kanemoto E, Sugimoto M, Machida A, Nakamura Y, Naito N, Kanzaki H, Miyazaki I, Asanuma M, Sendo T. Influence of nicotine on doxorubicin and cyclophosphamide combination treatment-induced spatial cognitive impairment and anxiety-like behavior in rats. Naunyn Schmiedebergs Arch Pharmacol. 2017;390(4):369-378. DOI: $10.1007 / \mathrm{s} 00210-016-1338-\mathrm{Z}$

16. Bano S, Ghafoor S, Naseem N. Effect of thyroid hormone on the histology of rat submandibular salivary gland during postnatal development. J Pakistan Dent Assoc. 2018;27(1):37-42. DOI: 10.25301/jpda.271.37

17. Reagan-Shaw S, Nihal M, Ahmad N. Dose translation from animal to human studies revisited. FASEB J. 2008;22(3):659-661. DOI: 10.1096/fj.07-9574LSF

18. Viberg H, Eriksson P, Gordh T, Fredriksson A. Paracetamol (acetaminophen) administration during neonatal brain development affects cognitive function and alters its analgesic and anxiolytic response in adult male mice. Toxicol Sci. 2014;138(1):139-147. DOI: 10.1093/toxsci/kft329

19. Al-Khafaf AI, Ismail HK, Al-Saidya AM. Histopathological effects of experimental exposure to lead on nervous system in albino female rats. Iraqi $\mathrm{J}$ Vet Sci. 2021;35(1):45-48. DOI: 10.33899/ijvs.2019.126248.1273

20. Ismail HK. Histopathological alterations of male and female reproductive systems induced by alloxan in rats. Iraqi J Vet Sci. 2020 May 11;35(2):223-6. DOI: $10.33899 /$ ijvs.2020.126626.1351

21. Ibrahim HM, Zommara MAE, Elnaggar ME. Ameliorating effect of selenium nanoparticles on cyclophosphamide induced hippocampal neurotoxicity in male rats: light, electron microscopic and immunohistochemical study. Folia Morphol. 2020; DOI: 10.5603/FM.a2020.0117

22. Amin SN, Younan SM, Youssef MF, Rashed LA, Mohamady I. Open Peer Review A histological and functional study on hippocampal formation of normal and diabetic rats. F1000Res. 2013;(May):1-23. DOI: 10.12688/f1000research.2-151.v1

23. Licht T, Kreisel T, Biala Y, Mohan S, Yaari Y, Anisimov A, Alitalo K, Keshet E. Age-dependent remarkable regenerative potential of the dentate gyrus provided by intrinsic stem cells. J Neurosci. 2020;40(5):974-995. DOI: 10.1523/JNEUROSCI.1010-19.2019

24. Blaise JH, Park JE, Bellas NJ, Gitchell TM, Phan V. Caffeine consumption disrupts hippocampal long-term potentiation in freely behaving rats. Physiol Rep. 2018;6(5):1-8. DOI: 10.14814hy2.13632

25. Philippot G, Hallgren S, Gordh T, Fredriksson A, Fredriksson R, Viberg H. A cannabinoid receptor type 1 (CB1R) agonist enhances the developmental neurotoxicity of acetaminophen (Paracetamol). Toxicol Sci. 2018;166(1):203-212. DOI: 10.1093/toxsci/kfy199

26. Mohammed ET, Safwat GM. Assessment of the ameliorative role of selenium nanoparticles on the oxidative stress of acetaminophen in some tissues of male albino rats. Beni-Suef Univ J Basic Appl Sci. 2013;2(2):80-85. DOI: 10.1016/j.bjbas.2013.01.003

27. Sadek KM, Lebda MA, Abouzed TK. The possible neuroprotective effects of melatonin in aluminum chloride-induced neurotoxicity via antioxidant pathway and Nrf2 signaling apart from metal chelation. Environ Sci Pollut Res. 2019;26(9):9174-9183. DOI: 10.1007/430-9

28. Al-allaf LIK, Al-neaimy WM. The Histologic Effect of Baclofen in Rat' s brain: An Experimental Study. 2020;17(1):57-74. DOI: 10.33899/iphr.2020.167598

29. Salah BA. Histopathological effect of fluoxetine drug on the brain of pregnant mice and their embryos. Iraqi J Vet Sci. 2020;34(1):71-76. DOI: $10.33899 /$ ijvs.2019.125467.1006

30. Fadel M, Mohammad FK. Effect of diphenhydramine and phenobarbital in the concentration of glutathione and malondialdehyde and glucose in plasma and brain of chicks treated with pentylenetetrazol. Iraqi J Vet Sci. 2019 Sep 1;33(2):97-104. DOI: $\underline{10.33899 / \mathrm{ijvs} .2019 .163173}$

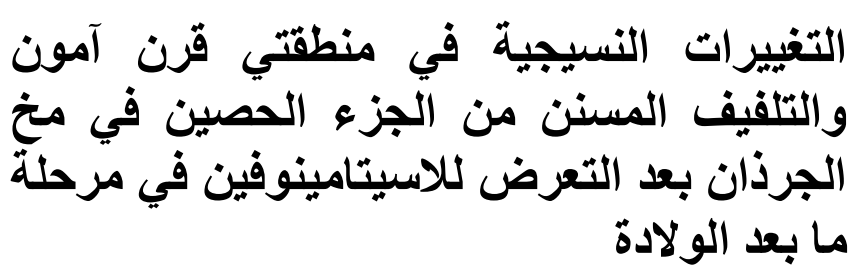

سيف محمد البوحسين و لمى إبراهيم العلاف

فرع التشريح، كلية الطب، جامعة الموصل، الموصل، العراق

الخلاصة

سجل الباحثون إن التعرض للاسيتامينوفين بعد الو لادة يمكن أن

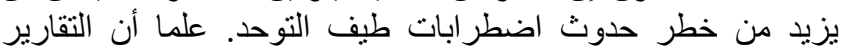

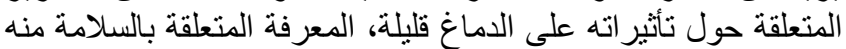
قليلة وهناك تجاهل تقليدي للمحاولات السريرية من قبل المستهلكين لها له

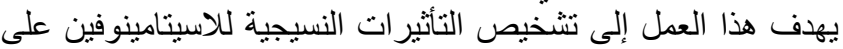

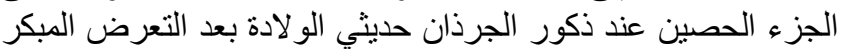

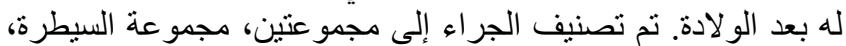

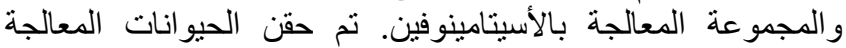

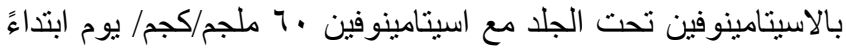

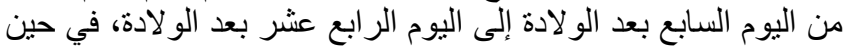

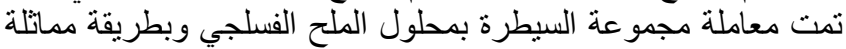

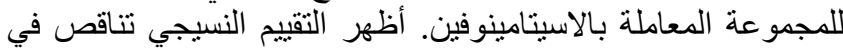

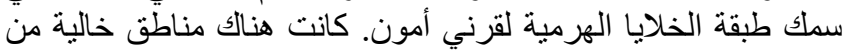

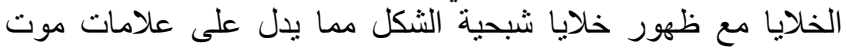

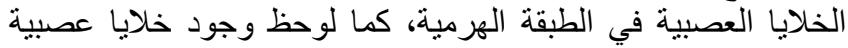

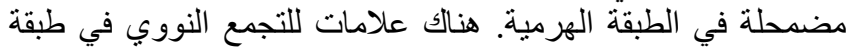

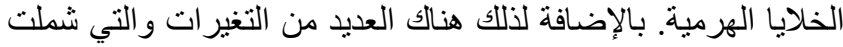

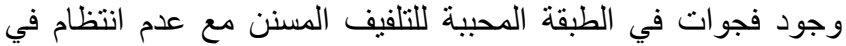

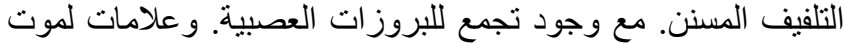
الخلايا المبرمج في الطبقة المحببة ومنطقة النقير في الثرائح العائدة للتلفيف المسنن للجرذان مع ظهور الكثير من الخلاياً النجمية والخلايا

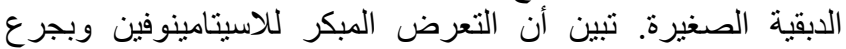

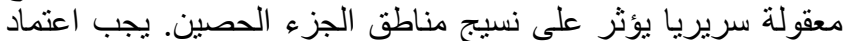

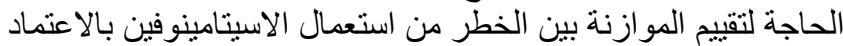

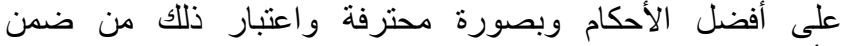

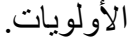

